\title{
O ensino da tabuada no contexto das ações de estudo propostas por Davýdov e colaboradores*
}

EDISÉIA SUETHE FAUST HOBOLD Universidade do Sul de Santa Catarina, Tubarão, SC, Brasil

JOSÉLIA EUZÉBIO DA ROSA Universidade do Sul de Santa Catarina, Tubarão, SC, Brasil

\section{RESUMO}

Esta investigação foi desenvolvida no contexto da educação matemática, com base nos pressupostos da teoria histórico-cultural, com ênfase na obra de Davýdov, doutor em psicologia e seguidor de Vigotski. Davýdov coordenou o processo de elaboração de uma proposta para o ensino de matemática na Rússia e efetivou sua publicação por meio de livros didáticos e manuais de orientação ao professor. Esse material é a fonte de dados da pesquisa que consistem nas tarefas davydovianas e cujo objetivo se constitui em investigar o movimento conceitual impresso na proposição davydoviana para o ensino de tabuada por meio das ações de estudo. Os resultados indicam que a proposição do autor, para o ensino da tabuada, contempla a inter-relação das significações aritméticas, algébricas e geométricas no movimento que envolve o geral, universal, particular e singular no contexto de ações de estudo.

\section{PALAVRAS-CHAVE}

educação matemática; teoria histórico-cultural; Davýdov; proposição de ensino; tabuada.

* Fontes financiadoras desta pesquisa: Conselho Nacional de Desenvolvimento Científico e Tecnológico (CNPq) e Fundo de Apoio à Manutenção e ao Desenvolvimento da Educação Superior no Estado de Santa Catarina (FUMDES/SC). 


\title{
TEACHING THE MULTIPLICATION TABLE IN THE CONTEXT OF STUDY ACTIONS PROPOSED BY DAVÝDOV AND CO-WORKERS
}

\begin{abstract}
This research was developed in the Mathematics education context based on the assumptions of the cultural-historical theory, with emphasis on the work of Davýdov, doctor in psychology and Vygotsky's follower. Davýdov coordinated the process for elaboration of a proposal for mathematics teaching in Russia, and published through textbooks and teacher's guiding books. This material is the data source for the research, which consisted in Davýdov's tasks, and the aim is constituted in the investigation of the conceptual movement, Davýdov's proposition to teach the multiplication table through study actions. The results indicate the author's proposition for teaching the multiplication table contemplates the interrelations of arithmetic, algebraic and geometrical significations on the movement that involves the general, universal, particular and singular on the context of study actions.
\end{abstract}

\section{KEYWORDS}

mathematics education; cultural-historical theory; Davýdov; teaching proposition; multiplication table.

\section{LA ENSEÑANZA DE LA TABLA DE MULTIPLICAR EN EL CONTEXTO DE LAS ACCIONES PROPUESTAS POR DAVÝDOV Y COLABORADORES}

\section{RESUMEN}

La investigación fue desarrollada en el contexto de la educación matemática basada en los presupuestos de la teoría histórico-cultural con énfasis para la obra de Davýdov, doctor en psicología y seguidor de Vigotski. Davýdov coordinó el proceso de elaboración de una propuesta para la enseñanza de matemática en Rusia, y publicó por medio de libros didácticos y manuales de orientación para profesores. Ese material es la fuente de datos de la investigación, que consiste en las tareas de Davýdov, y cuyo objetivo es constituido en investigar el movimiento conceptual impreso en la proposición de Davýdov para la enseñanza de la tabla de multiplicar, por medio de acciones de estudio. Los resultados indican que la proposición del autor para la enseñanza de la tabla de multiplicar contempla la interrelación de las significaciones aritméticas, algébricas y geométricas en el movimiento que involucra lo general, universal, particular y singular en el contexto de acciones de estudio.

\section{PALABRAS CLAVE}

educación matemática; teoría histórico-cultural; Davýdov; proposición de enseñanza; tabla de multiplicación. 


\section{INTRODUÇÃO}

No presente artigo, apresentamos os resultados de uma pesquisa ${ }^{1}$ sobre o modo de organização do ensino de tabuada proposto por Davýdov e colaboradores com base nos pressupostos da teoria histórico-cultural. Nessa perspectiva, a tabuada é constituída por um sistema de relações de multiplicidade, cujos resultados (produtos) conformam uma sequência numérica na qual cada termo posterior é o anterior adicionado ao valor da tabuada correspondente.

Com um projeto de formação de um novo homem, Davýdov almejava que a escola "ensinasse os alunos a orientarem-se com autonomia na informação científica e em qualquer outra esfera do conhecimento" (Libâneo e Freitas, 2013, p. 315). Suas investigações foram fundamentadas na teoria elaborada por Vigotski e desenvolvida por Luria, Leontiev, Galperin, Elkonin, Zaporozhets, entre outros colaboradores. Davýdov foi o pesquisador da terceira geração dessa escola que mais se destacou em psicologia pedagógica (Libâneo e Freitas, 2013; Rosa, 2012).

A proposição davydoviana para o ensino de matemática apresenta uma base teórico-metodológica que reúne princípios psicológicos em virtude de objetivos pedagógicos e didáticos que promovem nos estudantes o desenvolvimento do pensamento teórico-científico (Davýdov, 1982). Esse é o tipo de pensamento que possibilita o acesso à essência dos objetos.

[...] é a conexão interna que, como fonte única, [...] determina todas as outras especificidades particulares do todo. Trata-se de conexões objetivas que, em sua dissociação e manifestação, asseguram a unidade dos aspectos do todo; isto é, dão ao objeto um caráter concreto. (Davídov, 1988, p. 147)²

Davýdov também dedicou seus estudos científicos a questões referentes às ações mentais, fundamentadas na teoria criada por Galperin nos anos de 1950 (Shuare, 1990). De 1959 a 1983, trabalhou com Elkonin no Instituto de Psicologia Geral e Pedagogia da Academia de Ciências Pedagógicas da União Soviética. Nesse instituto eram realizadas investigações experimentais sobre as relações entre educação e desenvolvimento por dois grupos de pesquisadores: o de Zankov, na Escola Experimental n. 17, em Kharkov, Ucrânia; e o de Elkonin e Davýdov, na Rússia. No entanto, foram as pesquisas do segundo grupo, desenvolvidas na Escola Experimental n. 91, que propiciaram a formulação do sistema de ensino Elkonin-Davýdov, também denominado ensino desenvolvimental (Libâneo e Freitas, 2013). Na referida escola foram realizadas pesquisas, por mais de vinte e cinco anos, sobre a formação do pensamento teórico dos estudantes. Estas investigações ocorreram, principalmente, no ensino fundamental, nas disciplinas de matemática, língua russa, literatura, ciências, artes plásticas e música (Libâneo e Freitas, 2013).

1 Artigo elaborado com base na dissertação de mestrado de Ediséia Suethe Faust Hobold intitulada Proposiçóes para o ensino da tabuada com base nas lógica formal e dialética, sob orientação de Josélia Euzébio da Rosa.

2 As traduções são livres e de responsabilidade das autoras. 
$\mathrm{Na}$ década de 1980, as pesquisas sobre o ensino desenvolvimental estenderam-se para o ensino de $5^{\mathrm{a}}$ a $8^{\mathrm{a}}$ séries.

Davýdov e Elkonin detectaram que a atividade de estudo não estava presente nas escolas. Tal fato os levou a propor, em 1960, a elaboração de novos programas para o ensino fundamental, com o objetivo de desenvolver o pensamento teórico dos estudantes. Para tanto, Davýdov ${ }^{3}$ com os colaboradores Gorbov, Mikulina e Savieliev elaboraram e desenvolveram, em caráter investigativo, uma proposição para o ensino de matemática que fora depois publicada em livros didáticos, manuais de orientação ao professor, entre outros. Esse material constitui a fonte de dados desta pesquisa: as tarefas davydovianas. Estas foram extraídas dos livros didáticos referentes ao $2^{\circ}$ e $3^{\circ}$ anos do ensino fundamental (Davýdov et al., 2012, 2009). A resolução das tarefas está em conformidade com os manuais de orientação ao professor (Gorbov, Mikulina e Savieliev, 2009; Gorbov e Mikulina, 2003).

As reflexões sobre a experiência realizada em sala de aula, pelo grupo de colaboradores de Davýdov, possibilitaram um amplo processo de elaboração e reelaboração da proposta. Esse movimento é refletido nos manuais de orientação ao professor em forma de relato de experiência. Sem essas reflexões não é possível conceber as tarefas apresentadas no livro didático como expressão dos pressupostos oriundos da teoria histórico-cultural. A aparência externa das tarefas davydovianas é semelhante aos exercícios apresentados nos livros didáticos brasileiros (Rosa, 2012).

No primeiro contato com o material didático davydoviano, detectamos algumas tarefas que indicavam a existência de sistematização da tabuada nos livros do $2^{\circ}$ e $3^{\circ}$ anos do ensino fundamental. Porém, tivemos dificuldade em identificar quais tarefas eram referentes à tabuada, pois os livros didáticos e os manuais de orientação ao professor foram publicados no idioma russo. A análise desse material foi realizada com o auxílio da professora de língua russa Elvira Kim. ${ }^{4}$

A proposição davydoviana não é apresentada de forma fragmentada por conceitos: primeiro um, depois outro e assim por diante. Ao contrário, os conceitos são apresentados de modo interconectado, no contexto de um sistema conceitual. Neste, um conceito contribui para o desenvolvimento do outro e conforma um sistema integral. $\mathrm{O}$ "conceito científico pressupõe necessariamente outra relação com objetos, só possível no conceito, e esta outra relação com o objeto, contida no conceito científico, por sua vez, pressupõe necessariamente a existência de relações entre os conceitos" (Vigotski, 2000, p. 294).

Enfim, no emaranhado conceitual, foi difícil identificar quais tarefas eram referentes, especificamente, ao ensino de tabuada. Além disso, nos questionávamos: se Davýdov e colaboradores contemplam o sistema conceitual (Rosa, 2012), então podemos considerar que tabuada é um conceito? O que é conceito?

3 Importante aqui trazer a grafia original do nome desses autores: Davýdov (ДАВЫДОВ) Gorbov (ГОРБОВ), Mikulina (МИКУЛИНА) е Savieliev (САВЕЛЬЕВА).

4 Atualmente leciona a disciplina de russo no Centro de Idiomas da Universidade Federal do Paraná (UFPR). 
Se tabuada é um conceito, qual o seu conteúdo? Como Davýdov e colaboradores propõem o processo de generalização, abstração e memorização da tabuada em sua proposição de ensino?

As reflexões anteriormente apresentadas contribuíram com o processo de delimitação do objetivo de pesquisa: investigar o movimento conceitual impresso na proposição davydoviana para o ensino de tabuada no contexto das ações de estudo. Para tanto, foi necessário estudar o material didático referente ao $2^{\circ}$ e $3^{\circ}$ anos do ensino fundamental; extrair e reproduzir as tarefas particulares; revelar a relação que permite determinar a essência da tabuada; explicitar as ações de estudo; e estudar a base teórico-metodológica.

Trata-se de uma pesquisa de natureza teórica, e o materialismo históricodialético foi adotado como método de investigação. Em concernência com o método, orientamo-nos em três pares de categorias que consideramos fundamentais no processo do conhecer: geral/particular, universal/singular e abstrato/concreto. Cada uma dessas categorias "revela uma determinada face das complexas contradições da realidade em seu movimento e somente a análise de todas essas faces, em síntese, pode reproduzir, no pensamento, a representação do objeto"(Rosental, 1962, p. 299).

Os referidos pares de categorias lógicas apresentam contradições que estão em constante movimento. Umas categorias "se transformam em outras em consonância com o desenvolvimento das propriedades e relações dos fenômenos e processos reais, da realidade objetiva, propriedades e fenômenos refletidos nas contradições principais" (Rosental, 1962, p. 277). Isso significa que as contradições existentes entre as categorias, no processo de desenvolvimento do conhecimento, transformam-se em outras. Por exemplo, o concreto, em determinado momento do processo de investigação, transforma-se em abstrato e vice-versa. Essa transformação é marcada por um processo de redução-ascensão e apresenta-se como estágio de superação em relação ao inicial.

Adotamos os seguintes procedimentos metodológicos: inicialmente identificamos a orientação metodológica apresentada nos manuais de orientação ao professor correspondente às tarefas indicadas nos livros didáticos. Na sequência, procedemos ao estudo concomitante das tarefas com as orientações, base para a identificação de que Davýdov e colaboradores desenvolvem a tabuada a partir de um sistema conceitual (conceito de número, relação de multiplicidade, divisibilidade, relação parte-todo, adição, subtração, entre outros). Também contemplamos as tarefas geradoras das condições de origem da tabuada na proposição davydoviana (Hobold, 2014). Porém, para o presente artigo, selecionamos apenas cinco tarefas referentes à tabuada e as reproduzimos fidedignamente, inclusive com a resolução proposta nos manuais de orientação ao professor. Além disso, prosseguimos com o estudo da base teórico-metodológica para revelar o movimento conceitual da tabuada na proposição davydoviana.

A análise possibilitou revelar que a proposição davydoviana, para o ensino da tabuada, contempla a inter-relação das significações aritméticas, algébricas e geométricas no movimento que envolve o geral, universal, particular e singular por meio da tarefa de estudo composta por ações, conforme apresentaremos a seguir. 


\section{AS TAREFAS NO CONTEXTO DAS AÇÕES DE ESTUDO NA PROPOSIÇÃO DAVYDOVIANA}

Davýdov, com seus colaboradores, estruturou sua proposição de ensino em conformidade com a atividade de estudo (Davýdov, 1982). Nesse contexto, os autores em referência apresentam tarefas principais de estudo para cada sistema conceitual. Cada tarefa principal é composta de ações que são desenvolvidas por meio de um sistema de tarefas particulares correspondentes aos exercícios, ou atividades nas proposições brasileiras.

A finalidade da primeira tarefa principal de estudo, em matemática, consiste na "obtenção e o emprego do número como meio especial de comparação das grandezas" (Davídov, 1988, p. 188). Na segunda, o foco incide nos conceitos de adição e subtração, inseridos em um sistema mais amplo, que envolve relação parte-todo, resolução de problemas, equações, entre outros (Davídov, 1988).

Os conceitos de multiplicação e divisão, por sua vez, constituem o núcleo do sistema conceitual referente à terceira tarefa de estudo. Porém, Davýdov e colaboradores contemplam as relações de multiplicidade e divisibilidade desde o primeiro ano escolar (Davídov, 1988).

As ações de estudo são compostas de um sistema de tarefas particulares que objetivam a finalidade almejada, qual seja: a apropriação de determinado conceito ou sistema conceitual. $\mathrm{Na}$ especificidade da presente investigação, a análise incide na terceira tarefa de estudo (sistema conceitual de multiplicação e divisão), com recorte para o conceito de tabuada.

Vale salientar que não se trata de uma sequência fragmentada e linear na qual, para cada ação, há um conjunto de tarefas particulares específicas. Em alguns casos, uma mesma tarefa particular atende a uma ou mais ações de estudo. A referência de análise, no presente artigo, recai sobre a terceira tarefa de estudo, com recorte para o conceito de tabuada, no contexto das quatro primeiras ações (Davídov,1988, p. 181, grifos do original):

1. Transformação dos dados da tarefa de estudo com a finalidade de revelar a relação universal do objeto estudado;

2. Modelação da relação universal na forma objetal, ${ }^{5}$ gráfica e literal;

3. Transformação do modelo da relação universal para o estudo de suas propriedades em forma pura;

4. Construção de um sistema de tarefas particulares que podem ser resolvidas por um procedimento geral.

Para desenvolver a primeira ação de estudo intitulada transformação dos dados da tarefa de estudo com a finalidade de revelar a relação universal do objeto estudado, Davýdov e colaboradores apresentam situações que geram a necessidade dos conceitos em seu caráter teórico. Assim, o ponto de partida, na proposição davydoviana, é a observação e a transformação dos dados reais da tarefa, não solucionáveis pelos

5 A modelação da relação universal, na forma objetal, refere-se à revelação dos elementos que a constituem por meio das grandezas discretas e contínuas inerentes aos objetos e fenômenos. 
procedimentos conhecidos pela criança. A finalidade é revelar e distinguir a relação completamente definida de certo sistema integral ${ }^{6}$ (Davídov, 1988), na especificidade deste, a tabuada. Tal relação é constituída pelos dados da tarefa e atua como fonte de todas as tabuadas (do sistema integral). Mas qual é a relação essencial da tabuada? Quais são os dados que permeiam todas as tarefas particulares referentes à tabuada? Para responder aos questionamentos, analisemos a Tarefa 1.

Tarefa 1: Complete os esquemas de setas e compare as áreas com medidas $M$ e A (Figura 1) (Davýdov et al., 2012).

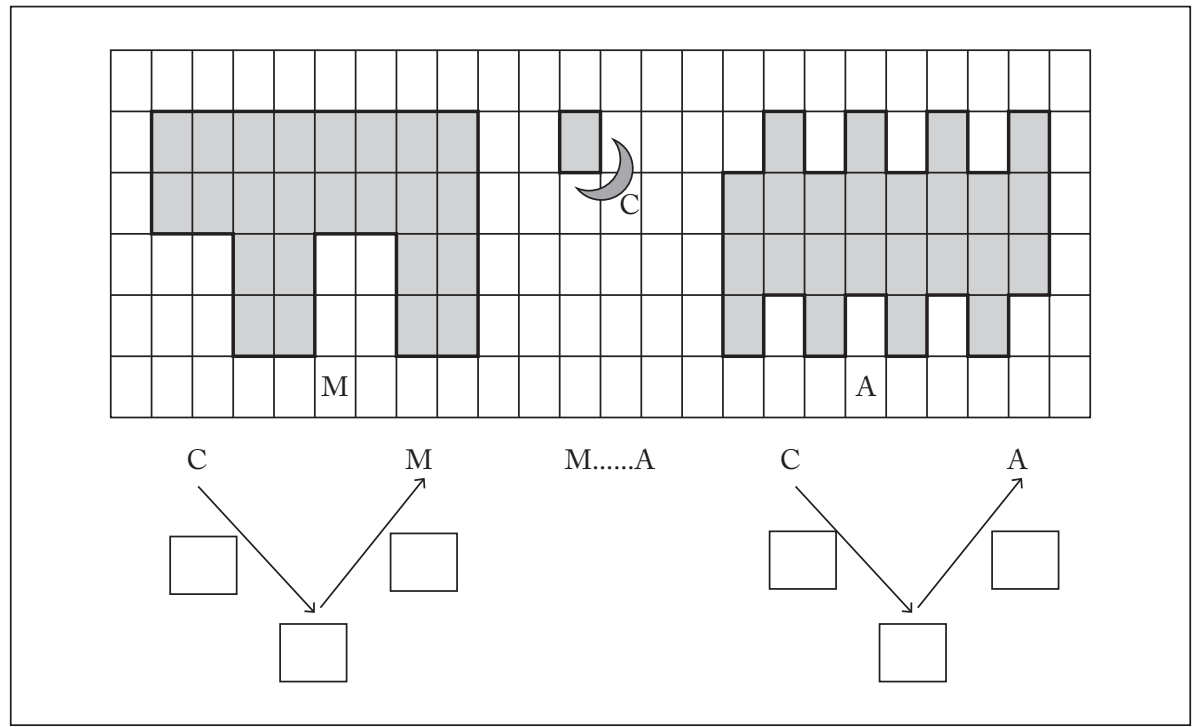

Figura 1 - Tarefa 1: registro no esquema a partir da grandeza área

Fonte: Elaboração nossa com base na proposição davydoviana (Davýdov et al., 2012, p. 64).

O registro no esquema de setas (Figura 1) indica que as superfícies foram compostas pela mesma unidade de medida básica $(\mathrm{C})$, porém as unidades intermediárias são diferentes (Gorbov, Mikulina e Savieliev, 2009).

A Figura 1 mostra, implicitamente, que a unidade de medida intermediária é composta de quatro (4) unidades básicas. Pela relação entre a área com medida $\mathrm{M}$ e a unidade de medida intermediária, é possível concluir que esta cabe seis (6) vezes em M. Os números (6 e 4) são introduzidos, conforme Figura 2, no esquema de setas (Gorbov, Mikulina e Savieliev, 2009).

$\mathrm{Na}$ segunda situação de análise, a unidade de medida intermediária (colunas) é composta de três (3) unidades básicas, que se repete por oito (8) vezes. Os resultados da medição são escritos no esquema. Como as unidades de medida

6 Trata-se da relação válida para todas as tabuadas, em sua totalidade, e não apenas para algumas tabuadas em particular. 


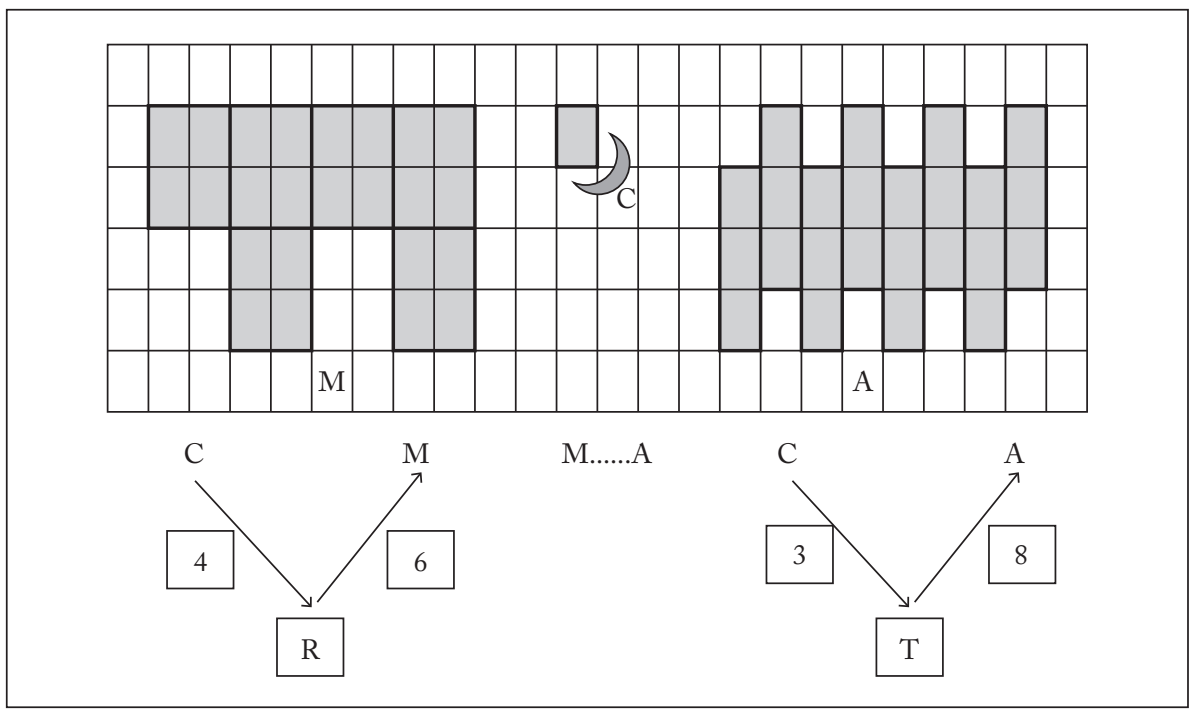

Figura 2 - Tarefa 1: determinação da unidade de medida intermediária

Fonte: Elaboração nossa com base na proposição davydoviana (Davýdov et al., 2012).

intermediária são diferentes, serão representadas por letras distintas (Gorbov, Mikulina e Savieliev, 2009).

O professor informa que é preciso comparar as áreas das duas figuras. Relata que um estudante, de outra escola, afirmou que a área com medida $\mathrm{M}$ é maior que a área com medida $\mathrm{A}$, porque a unidade de medida intermediária, da primeira, é maior (Gorbov, Mikulina e Savieliev, 2009). Essa afirmação está correta?

Para comparar as medidas, é necessário conhecer o total das unidades de medidas básicas em cada superfície. Para continuar o processo de medição e informação do procedimento adotado, o professor insere a seta superior no esquema e um ponto de interrogação (Figura 3), que representa o total de unidades básicas (Gorbov, Mikulina e Savieliev, 2009).

A operação adequada para determinar o valor desconhecido (total de unidades básicas) quando se conhece a unidade de medida intermediária e a quantidade de vezes que ela se repete é a de multiplicação. $O$ resultado obtém-se com o auxílio da reta numérica.

Constroem-se duas retas, uma para calcular o valor de $\mathrm{M}$ e outra para o valor de A. Na primeira delas (Figura 4) adota-se, como procedimento de identificação da unidade de medida intermediária, um arco composto de quatro (4) unidades básicas, o qual se repete por seis (6) vezes (Figura 4). O final do último arco incidirá sobre o número vinte e quatro (24), total de unidades de medidas básicas. Na segunda reta, referente à superfície de medida $\mathrm{A}$, cada unidade de medida intermediária é representada por um arco composto de três (3) unidades básicas. Como surgem oito (8) arcos, o resultado é vinte e quatro (24). Os pontos de interrogação são substituídos pelos respectivos resultados (Gorbov, Mikulina e Savieliev, 2009). 


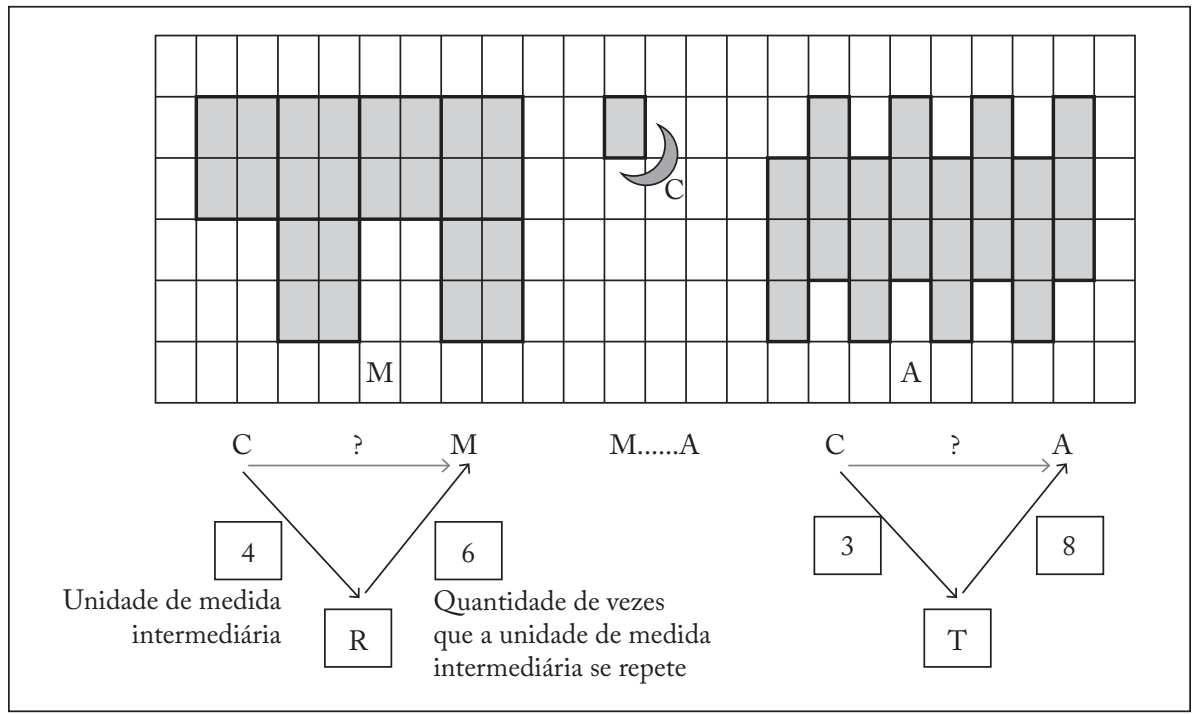

Figura 3-Tarefa 1: o esquema é completado pela reta superior

Fonte: Elaboração nossa com base na proposição davydoviana (Davýdov et al., 2012).

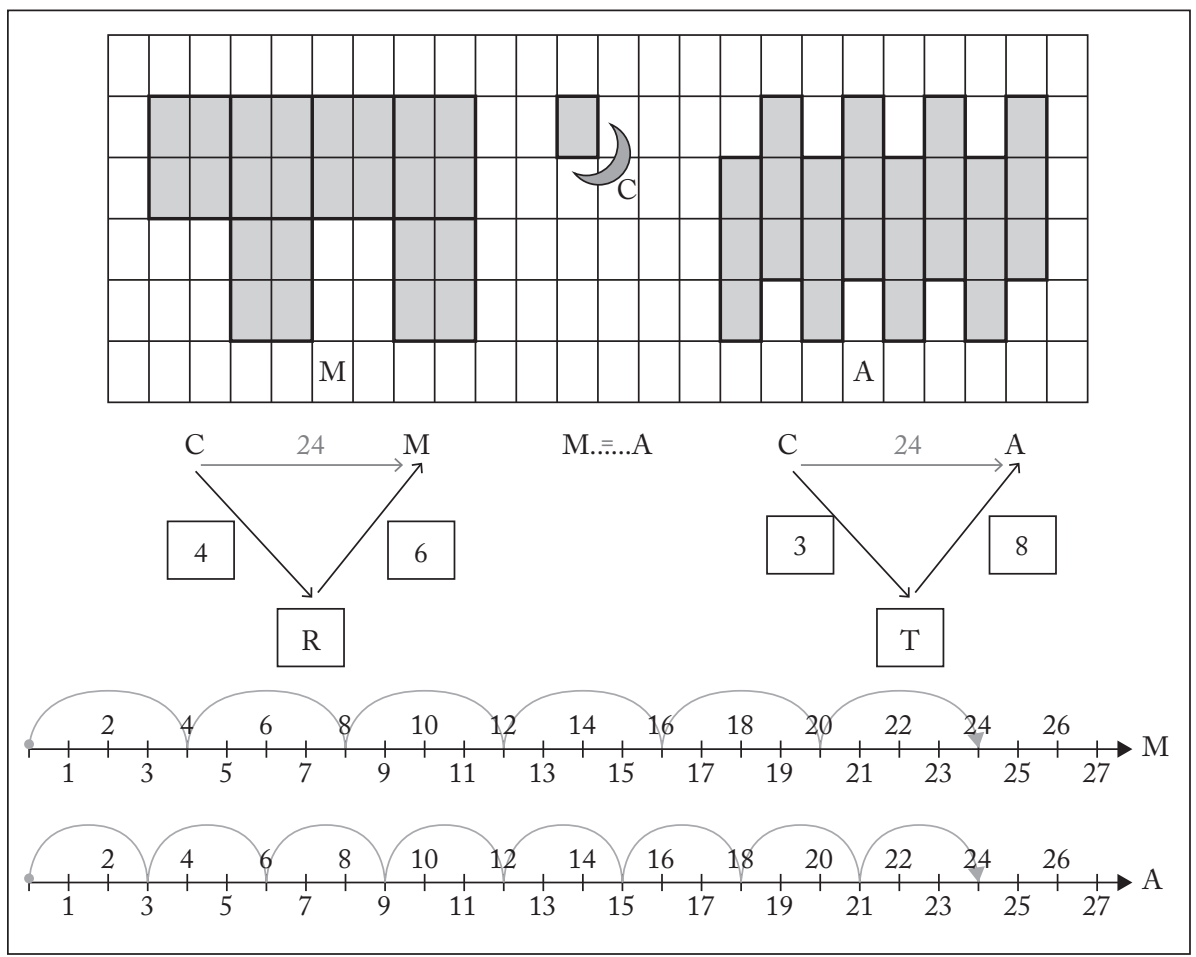

Figura 4 - Tarefa 1: construção da reta e determinação do total de unidades básicas

Fonte: Elaboração nossa com base na proposição davydoviana (Davýdov et al., 2012). 
Ambas as superfícies são compostas de vinte e quatro (24) unidades de medidas básicas; logo, $\mathrm{M}=\mathrm{A}$ (Figura 4). A tarefa particular em análise é uma das apresentadas na primeira ação de estudo. Os dados que possibilitam a revelação da relação universal da tabuada são a unidade básica, intermediária e total de unidades básicas e intermediárias. São esses dados que compõem a relação universal do conceito de tabuada e permeiam todas as tarefas particulares. Inicialmente, cada tarefa particular é apresentada na forma objetal (áreas das superfícies), a partir da relação entre grandezas.

Trata-se do concreto ponto de partida. Este não revela imediatamente as conexões internas da tabuada, que serão mostradas no processo do conhecer. O concreto, nesse estágio, pode ser visível ou não. "É visível em suas manifestações concretas, em seu exterior, porém não é como o concreto, em que as manifestações externas e imediatas estão ligadas por sua essência interna, para as leis de sua existência e desenvolvimento" (Ilienkov, 2006, p. 159). Isto é, o concreto ponto de partida apresenta todas as características externas e internas. Porém as relações internas somente são reveladas no processo do conhecimento, como concreto pensado, ponto de chegada.

Vale esclarecer que a transformação dos dados, prevista na primeira ação de estudo, ocorre em várias tarefas particulares. Em algumas são consideradas as grandezas discretas, em outras, as contínuas. Desse modo, as unidades de medidas são unidades de comprimentos, áreas, volumes, entre outros. Além disso, as unidades básicas, compostas ou não, são transformadas em unidades intermediárias. Essa variedade de grandezas e de unidades de medida evita, de acordo com Davýdov (1982), a generalização empírica do conceito.

$\mathrm{Na}$ tarefa em análise, os dados são modelados por meio das relações entre grandezas (as áreas das superfícies com medida $\mathrm{M}$ e A). Esse processo corresponde a uma parte da segunda ação de estudo: modelação da relação universal na forma objetal, gráfica e literal. Os dados da tarefa foram modelados na forma objetal, por meio da relação entre as áreas expressas na malha quadriculada (Figura 2). Em seguida, os mesmos dados foram modelados na forma gráfica, por meio dos esquemas de setas, retas numéricas e arcos (Figuras 3 e 4).

Esse movimento de abstração da relação essencial da tabuada culminará com sua representação por meio de letras: o modelo é "um sistema representado mentalmente ou realizado materialmente que, refletindo ou reproduzindo o objeto de investigação, é capaz de substituí-lo de modo que seu estudo nos dê uma nova informação sobre este objeto" (Shtoff, 1966 apud Davídov, 1988, p. 133).

Os modelos não são

[...] simples substitutos dos objetos. As condições de criação, por exemplo, de um modelo material [objetal], são tais que "em seus elementos e nas relações entre eles, estão separadas e fixadas as vinculações essenciais e necessárias que formam uma estrutura completamente determinada" (Shtoff, 1966, p. 281). Os modelos são uma forma peculiar de abstração, na qual as relações essenciais do objeto estão fixadas nos nexos e relações visualmente perceptíveis e representadas, de elementos materiais e semióticos (Davídov, 1988, p. 134). 
O estudo do modelo constitui o "trabalho interno imprescindível no processo de assimilação dos conceitos teóricos e dos procedimentos generalizados de ação" (Davídov, 1988, p. 182). A percepção do "modelo material [objetal] pressupõe, simultaneamente, uma participação significativa do pensamento, a aplicação dos conhecimentos teóricos e da experiência acumulados. Ao perceber o modelo, o experimentador... compreende o que ocorre nele" (Shtoff, 1966 apud Davídov, 1988, p. 133). No processo de modelação, são contempladas as propriedades matemáticas que constituem o sistema conceitual, no qual a tabuada se insere, conforme a Tarefa 2.

Tarefa 2: Calcule cada produto (Figura 5) por meio das propriedades comutativa e distributiva da multiplicação (Gorbov, Mikulina e Savieliev, 2003).

$\begin{array}{ll}4 \times 1= & 4 \times 6= \\ 4 \times 2= & 4 \times 7= \\ 4 \times 3= & 4 \times 8= \\ 4 \times 4= & 4 \times 9= \\ 4 \times 5= & 4 \times 10=\end{array}$

Figura 5 - Tarefa 2: construção da tabuada do número quatro (4)

Fonte: Elaboração nossa com base na proposição davydoviana (Davýdov et al., 2009, p. 24).

As operações da Figura 5 são organizadas em uma sequência determinada e representam a tabuada do número quatro (4). O professor direciona a atenção para três multiplicações conhecidas $(4 \times 1=\ldots, 4 \times 2=\ldots$ e $4 \times 3=\ldots)$. Com base no estudo das tarefas anteriores, espera-se que as crianças saibam os resultados que são, respectivamente, 4, 8 e 12 (Gorbov e Mikulina, 2003).

O professor questiona: Como podemos determinar o produto da próxima multiplicação $(4 \mathrm{x} 4)$ sem utilizar a calculadora e a régua? É possível utilizar a regra da multiplicação pela soma. Isto é, a propriedade distributiva da multiplicação. Após ouvir as sugestões das crianças, o professor recorda a regra da multiplicação do número pela soma e questiona: Como podemos utilizá-la para determinar os próximos produtos? A sugestão é que o próximo valor desconhecido $(4 \times 4=\ldots)$ seja determinado a partir do último resultado obtido $(4 \times 3=12)$, pois $4 \times 4$ é equivalente a, por exemplo, $4 \times$ $(3+1)$ e $4 \times(2+2)$, conforme Figura 6 (Gorbov e Mikulina, 2003).

$\mathrm{O}$ mesmo procedimento estende-se para o cálculo de $4 \times 5=$. I Isto é, $4 \times 5=$ $4 \mathrm{x}(4+1) \rightarrow(4 \times 4)+(4 \times 1)=16+4=20$. O professor enfatiza que os resultados são obtidos a partir do valor comum (quatro).

$$
\begin{aligned}
4 \times 4 & =4 \times(3+1) & &
\end{aligned}
$$

Figura 6 - Tarefa 2: construção da tabuada do número quatro (4)

Fonte: Elaboração nossa com base na proposição davydoviana (Davýdov et al., 2009). 
Nos próximos cálculos, o professor adota o registro resumido: $4 \times 6=4 \times(5+1)$ $\rightarrow(4 \times 5)+(4 \times 1)=20+4=24$. Na sequência, o registro é reduzido um pouco mais: $4 \times 7=24+4=28$. Esse procedimento é adotado para o cálculo nos próximos fatores: $4 \times 8=28+4=32,4 \times 9=32+4=36$ e $4 \times 10=36+4=40$ (Gorbov e Mikulina, 2003). Ao final, a tabuada é organizada do seguinte modo (Figura 7 ).

$$
\begin{array}{ll}
4 \times 1=4 & 4 \times 6=24 \\
4 \times 2=8 & 4 \times 7=28 \\
4 \times 3=12 & 4 \times 8=32 \\
4 \times 4=16 & 4 \times 9=36 \\
4 \times 5=20 & 4 \times 10=40
\end{array}
$$

Figura 7 - Tarefa 2: sistematização da tabuada do número quatro (4)

Fonte: Elaboração nossa com base na proposição davydoviana (Davýdov et al., 2009).

O professor expõe que, além de construir a tabuada, também é necessário memorizar seus resultados (Gorbov e Mikulina, 2003). A tabuada do número quatro (4) é generalizada do seguinte modo (Figura 8).

$$
\begin{aligned}
& 4 \times 5=4 \times(4+1) \\
& 4 \times 6=4 \times(5+1) \\
& =4 \times(b+1)
\end{aligned}
$$

Figura 8 - Tarefa 2: generalização da tabuada do número quatro (4)

Fonte: Elaboração nossa com base na proposição davydoviana (Davýdov et al., 2009).

A Figura 8 indica a determinação de um novo resultado, em que o segundo fator da sentença seja composto pelo fator da sentença anterior $(b)$, mais uma unidade $(b+1)$. Isso traduz o movimento de generalização em conexão com o da abstração expresso na síntese: o resultado anterior mais quatro. Essa síntese atende ao último estágio da segunda ação de estudo davydoviana, qual seja, modelação dos dados da tarefa de estudo na forma literal, referente à tabuada do número quatro: $4 \mathrm{x}(\mathrm{b}+1)=\mathrm{c}$. Trata-se de uma nova generalização.

Um novo conceito, uma nova generalização não surge senão com base no conceito ou generalização anterior. Isto se manifesta nitidamente no fato de que, paralelamente ao aumento das generalizações algébricas, ocorre o aumento da liberdade de operações. Libertar-se da vinculação ao campo numérico é operação diferente de libertar-se da vinculação do campo visual. A explicação do aumento da liberdade proporcional ao aumento das generalizações algébricas está na possibilidade de um movimento inverso do estágio superior para o inferior, contido na generalização superior: a operação inferior já é vista como caso particular da superior. (Vigotski, 2000, p. 372)

Portanto, $4 \times(5+1)$ é um caso particular da generalização superior, expressa no modelo 4 x (b +1). De acordo com Davídov (1988, p. 132-133, passim), "a modelação é um tipo peculiar de idealização simbólico-semiótica [...] os símbolos e os 
signos são os meios de construção da objetivação idealizada" expressa nos modelos. Esses podem ser materiais ou mentais. Os modelos materiais estão relacionados com a atividade prática, admitem a transformação objetiva, enquanto os mentais envolvem "somente a transformação mental" (Davýdov, 1982, p. 313).

O modelo material, reproduzido por meio das relações entre grandezas ( $\mathrm{Ta}-$ refa 1), expressa as propriedades estruturais da tabuada (unidades de medida básica e intermediária, total de unidades básica e intermediária). Os modelos mentais semióticos podem ser representados algebricamente. Estes são compostos de elementos individuais que não apresentam semelhança externa com o modelo original (objetal), mas, em sua estrutura, reproduzem a estrutura do objeto (Shtoff, 1966 apud Davídov, 1988).

Os modelos de estudo constituem o trabalho internamente imprescindível no processo de apropriação dos conhecimentos teóricos (Davídov, 1988). Por meio de modelos, as tarefas da proposição davydoviana são organizadas de modo que possam propiciar o estudo das propriedades conceituais, a fim de revelar as conexões internas. Em outras palavras, revelar a "relação universal do objeto dado, no qual deve ser refletido no correspondente conceito teórico"(Davídov, 1988, p. 182).

Mas quais são as conexões internas que constituem a essência do conceito de tabuada? Essas são reveladas durante o desenvolvimento das quatro ações, inerentes à tarefa de estudo davydoviana. Para responder a essa questão, examinaremos a função de cada dado que compõe o modelo da tabuada em análise e suas inter-relações.

$\mathrm{Na}$ expressão literal do modelo universal para a tabuada do número quatro, temos: $4 \mathrm{x}(\mathrm{b}+1)=\mathrm{c}($ Figura 8$)$. O primeiro termo é fixo (4), este corresponde à medida intermediária. $\mathrm{O}$ segundo $(\mathrm{b}+1)$ é um operador composto pelo fator da sentença anterior, mais uma unidade de medida intermediária que, nesse caso, equivale a quatro. $\mathrm{O}$ operador $(\mathrm{b}+1)$ designa quantas vezes a unidade intermediária se repete. Em síntese, o segundo fator de cada sentença (operador) é composto pela soma do termo da sentença anterior, mais uma unidade. Dessas relações podemos inferir que o segundo fator conforma uma sequência numérica, na especificidade desse estudo, de números positivos $(1,2,3,4, \ldots)$.

Desse modo, Davýdov e colaboradores revelam as características internas, não observáveis diretamente nas grandezas, por meio do modelo da tabuada do número quatro (4), em interconexão com o modelo universal, válido para todas as tabuadas. Então, qual é o modelo universal? No modelo da tabuada do número quatro $(a \times(b+1)=c)$, o primeiro fator de cada sentença é um número fixo $(a)$, e o segundo $(b+1)$ conforma uma sequência de números positivos $(1,2,3,4, \ldots)$.

Em cada operação da sequência que configura a tabuada do número quatro $(4 \times 1=4,4 \times 2=8, \ldots)$, o produto do termo seguinte é composto pelo produto da operação anterior $(c)$ mais uma unidade de medida intermediária $(a): c+a$. Esse modelo, no contexto da matemática, é denominado Lei da Recorrência, pois, para encontrar determinado produto da sequência, é necessário recorrer ao anterior, o que permite atingir certo grau de generalização. Assim, na sucessão 4, 8, 12, $16, \ldots$, entende-se que, pela Lei de Recorrência, esta é formada pela soma de quatro unidades ao elemento imediatamente anterior (Panossian, 2014).

Portanto, para expressar a tabuada do número quatro (4) sem recorrer ao termo anterior, precisamos considerar a posição do segundo termo. Em outras 
palavras, no contexto da proposição davydoviana, a quantidade de vezes que a unidade de medida é tomada. É possível "encontrar termos da sequência sem que seja necessário escrevê-la completamente”(Panossian, 2014, p. 124). Nesse sentido, os recursos algébricos são fundamentais, pois possibilitam o reconhecimento e a expressão da lei de formação.

O modelo particular apresentado na Figura 8, para a tabuada do número quatro, $4 \times(b+1)$, é expressão do modelo universal válido para qualquer tabuada. Davýdov e colaboradores não explicitam o modelo universal em sua proposição de ensino. Porém é tarefa da investigação científica revelar a essência do objeto de estudo. Destarte, aqui cabe o seguinte questionamento: o que é necessário considerar para construir o modelo universal da tabuada?

Conforme mencionamos, o modelo universal não está dado explicitamente. Contudo, sua essência é revelada durante o processo de generalização e abstração, desencadeado no desenvolvimento do sistema de tarefas particulares, a partir das relações entre grandezas expressas algebricamente.

Por conseguinte, na especificidade da tabuada, é necessário considerar uma determinada relação entre grandezas. Nesta, os fatores que a compõem ocupam uma posição e conformam uma sequência numérica, na qual cada termo posterior é a soma do anterior mais uma unidade de medida intermediária, denominada de razão. Subjacente à proposição davydoviana sobre o registro resumido, no parágrafo que antecede a Figura 8 há a seguinte regularidade:

$$
\begin{aligned}
& 4 \times 6=4 \times(6-1)+4=24 \\
& 4 \times 7=4 \times(7-1)+4=28 \\
& 4 \times 8=4 \times(8-1)+4=32 \\
& 4 \times 9=4 \times(9-1)+4=36 \\
& \vdots \\
& a \times n=a \times(n-1)+a=c
\end{aligned}
$$

A partir de um longo processo de análise das regularidades que possibilitam o registro resumido, revelamos o modelo universal da tabuada. Na especificidade da tabuada do número quatro (4), temos: $4=a$; a sequência numérica $6,7,8,9, \ldots=n$; o produto..., $24,28,32,36, \ldots=\mathrm{c}$.

Desse modo,

associar o elemento à posição que ocupa produz outra generalização em que cada elemento é a multiplicação de quatro vezes a sua posição, assim o décimo elemento da sequência é 40, o centésimo, 400, e assim por diante, e para tanto não é preciso conhecer os elementos anteriores. Nesse caso, a sequência tem uma dimensão funcional no sentido de que relaciona as grandezas, posição do elemento na sequência, com o valor numérico do elemento [resultado]. (Panossian, 2014, p. 125)

Se considerarmos o décimo elemento da sequência, no modelo universal, temos $4 \times 10=4 \times(10-1)+4=40$. O modelo literal é válido também para os números racionais. Consideremos, por exemplo, $n=\frac{1}{2}$ e $n=-3$, ainda no con- 
texto da tabuada do número quatro. Substituindo os valores numéricos no modelo $a \mathrm{x}(n-1)+a=c$, temos:

$$
\begin{aligned}
& \text { Para } n=\frac{1}{2} \Rightarrow 4 \times\left(\frac{1}{2}-1\right)+4=\frac{4}{2}-4+4=2+4-4=2 \\
& \text { Para } n=-3 \Rightarrow 4 \times(-3-1)+4=-12-4+4=-12
\end{aligned}
$$

O modelo literal é válido para qualquer $n$, no campo dos racionais, independentemente da unidade de medida intermediária, posição em que o segundo fator se encontra e sentido (positivo ou negativo). Assim, a modelação algébrica da tabuada possibilita ultrapassar os limites dos números naturais e estende-se ao campo dos números racionais. Além disso, o modelo também é válido para qualquer tabuada em particular.

O modelo universal "é a lei, a essência dos fenômenos singulares, ou seja, é algo qualitativamente distinto em comparação com a simples soma de características das coisas singulares" (Davýdov, 1982, p. 243). A lei "é um dos modos de manifestar a universalidade" (Rosental e Straks, 1965, p. 258).

Por universal se entende a comunidade que existe objetivamente de traços, propriedades e características dos objetos e fenômenos singulares da realidade objetiva, ou também a similitude das relações e nexos entre eles. O universal é o que se repete através do múltiplo, do diverso ou do individual. (Sternin, 1965, p. 257, grifo do original)

O universal está intimamente vinculado com a categoria de essência (Sternin, 1965). Esta é o aspecto interno que expressa o nexo profundo, o que se mantém por meio das várias manifestações particulares. A "essência é aquilo sem o qual o objeto perde sua qualidade específica” (Sternin, 1965, p. 259). No modelo da tabuada, a essência consiste na relação de multiplicidade entre grandezas (por meio de unidades básicas e intermediárias), cujo resultado conforma uma sequência, na qual o produto posterior é uma unidade de medida intermediária maior que o anterior. Essa essência é expressa no modelo $a \times n=a \times(n-1)+a=c$.

Consequentemente, o universal está relacionado com a lei, que "expressa o nexo estável, essencial, interno e reiterado entre os fenômenos” (Rosental e Straks, 1965, p. 258). De acordo com o matemático russo Bernshléin (1947 apud Davídov, 1988, p. 134), "toda relação entre símbolos matemáticos reflete as correspondentes relações entre as coisas reais". Nessa direção, Davídov (1988, p. 134) afirma que os "modelos semióticos refletem as conexões e relações dos objetos reais e, nesse sentido, as relações e conexões entre os signos matemáticos [...] podem ser consideradas expressões visuais do original". As relações entre os objetos reais ocorrem por meio de suas grandezas.

Assim, na presente tarefa, foi possível revelar o modelo universal subjacente à proposição davydoviana para o ensino da tabuada. $\mathrm{Na}$ Tarefa 3 , apresentaremos a transformação do modelo, correspondente à terceira ação de estudo, por meio da análise de suas manifestações em diferentes particularidades. 
Tarefa 3: Calcule cada produto referente à tabuada do número cinco (5) (Figura 9) por meio das propriedades comutativa e distributiva da multiplicação (Davýdov et al., 2009).

\begin{tabular}{|ll|}
\hline $5 \times 1=$ & $5 \times 6=$ \\
$5 \times 2=$ & $5 \times 7=$ \\
$5 \times 3=$ & $5 \times 8=$ \\
$5 \times 4=$ & $5 \times 9=$ \\
$5 \times 5=$ & $5 \times 10=$ \\
\hline
\end{tabular}

Figura 9 - Tarefa 3: apresentação da Tabuada de cinco (5)

Fonte: Elaboração nossa com base na proposição davydoviana (Davýdov et al., 2009, p. 33).

A tarefa consiste na construção da tabuada do número cinco (5). O professor sugere que as crianças determinem os produtos a partir da tabuada dos números dois (2), três (3) e quatro (4), estudadas anteriormente. Assim, por meio da propriedade comutativa, que permite inverter o papel do multiplicando e do multiplicador, procedem-se os seguintes raciocínios (Figura 10).

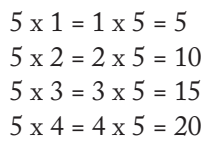

Figura 10 - Tarefa 3: apresentação da Tabuada de cinco (5)

Fonte: Elaboração nossa com base na proposição davydoviana (Davýdov et al., 2009).

Essa etapa inicial culmina com o registro dos respectivos resultados (Figura 11).

$\begin{array}{ll}5 \times 1=5 & 5 \times 6= \\ 5 \times 2=10 & 5 \times 7= \\ 5 \times 3=15 & 5 \times 8= \\ 5 \times 4=20 & 5 \times 9= \\ 5 \times 5= & 5 \times 10=\end{array}$

Figura 11 - Tarefa 3: determinação de alguns produtos da tabuada de cinco (5)

Fonte: Elaboração nossa com base na proposição davydoviana (Davýdov et al., 2009).

E a partir de 5 x 5, como proceder (Figura 11)? Vale lembrar que se trata de algo novo, que não foi estudado nas tabuadas anteriores; portanto, o método da propriedade comutativa se esgota. Procede-se, assim, como na tabuada do número quatro (4) (Tarefa 2), o cálculo do produto por meio da multiplicação de um número pela soma de outros dois. Assim, 5 x 5 pode ser escrito do seguinte modo $5 \times 5=$ $5 \times(4+1)$. Recorre-se à propriedade distributiva: $(5 \times 4)+(5 \times 1)=20+5$; logo, $5 \times 5=25$. A partir de então, toma-se como suporte os resultados dos produtos anteriores (Gorbov e Mikulina, 2003). Isto é (Figura 12).

Por fim, completam-se os demais registros da tabuada do número cinco (5) (Figura 13). 


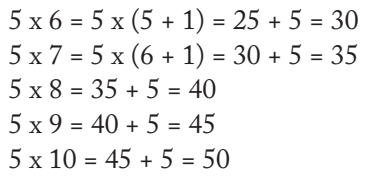

Figura 12 - Tarefa 3: determinação de alguns produtos da tabuada de cinco (5)

Fonte: Elaboração nossa com base na proposição davydoviana (Davýdov et al., 2009).

$$
\begin{aligned}
& 5 \times 1=55 \times 6=30 \\
& 5 \times 2=10 \quad 5 \times 7=35 \\
& 5 \times 3=155 \times 8=40 \\
& 5 \times 4=20 \quad 5 \times 9=45 \\
& 5 \times 5=255 \times 10=50
\end{aligned}
$$

Figura 13 - Tarefa 3: resultados da tabuada do número cinco (5)

Fonte: Elaboração nossa com base na proposição davydoviana (Davýdov et al., 2009).

A utilização da propriedade do produto de um número pela soma é, didaticamente, um dos modos de memorização das tabuadas. Para a tabuada do número cinco (5), o professor sugere que as crianças fechem seus cadernos que a contêm e pronunciem, em sequência crescente, todos os seus resultados. Esse processo, além de contribuir para a memorização, possibilita a constatação de que todos os produtos da tabuada apresentam uma sequência alternada de resultados, na qual os números constituintes terminam em zero (0) ou cinco (5) (Gorbov e Mikulina, 2003). As sequências "procuram captar o que há de regular nos fenômenos" (Panossian, 2014, p.123). Essa regularidade, na proposição em análise, consiste no universal expresso no modelo (Tarefa 2). Após ter alcançado o universal, o conhecimento

aspira para fixar as características específicas, as propriedades de grupos singulares de fenômenos dentro desse universal, isto é, para chegar ao individual e ao particular. $\mathrm{O}$ verdadeiro e pleno conhecimento consiste tanto em captar as características essenciais, gerais dos objetos, como em penetrar nas formas concretas com que o universal se manifesta. (Sternin, 1965, p. 273)

O conhecimento do universal ocorre por meio da investigação e confrontação de um grande número de fatos singulares (Sternin, 1965). O estudo da essência da tabuada implica a análise das manifestações singulares, pois é por meio destas que o universal se manifesta. Nesse sentido, é necessário conhecer a relação entre o universal e o singular, como o universal se manifesta nas diferentes singularidades. Para tanto, nosso pensamento move-se em um sentido inverso "em direção do particular para o singular" (Sternin, 1965, p. 274).

Em que consiste o particular? Para Sternin (1965), o particular é o elo que une o singular ao universal. Desse modo, no modelo da tabuada $a \times(n-1)+a=c$, o elo que une o universal ao singular consiste no número $a$, a unidade de medida intermediária. Com a variação de $a$, obtemos as diferentes tabuadas particulares $(a=4, a=5, a=6, \ldots)$. Mantendo o número $a$ fixo e variando o valor de $n$, obtemos 
as singularidades. Por exemplo, tomemos uma particularidade, a tabuada do número cinco (5), ao variarmos $n$, temos: $5 \times 1=5 ; 5 \times 2=10 ; 5 \times 3=15 ; \ldots$ Assim, a tabuada do número cinco (5) surge como resultado do estudo entre o universal, particular e singular, como conhecimento teórico.

Os conhecimentos teóricos surgem no processo de análise do papel e da função de certa relação peculiar, a relação de multiplicidade $a \times(n-1)+a=c$, dentro do sistema integral que, ao mesmo tempo, serve de fonte única para todas as suas manifestações singulares. Os conhecimentos teóricos, que surgem sobre a base da transformação mental dos objetos, refletem suas relações e conexões internas, isto é, as unidades básicas e intermediárias, o total de unidades básicas e intermediárias. As conexões internas saem dos limites das representações, tais como: os objetos, a reta numérica, os esquemas. A análise permite revelar a relação geneticamente inicial da tabuada como sua base universal ou essência.

A concretização dos conhecimentos teóricos consiste na dedução e explicação das manifestações particulares e singulares do sistema integral, a partir de seu fundamento universal. $\mathrm{Na}$ Tarefa 4 , apresentaremos a transformação do modelo por meio da análise de suas manifestações em diferentes particularidades. Esta constitui a terceira ação de estudo.

Tarefa 4: Determine a diferença entre as medidas A e B (Gorbov e Mikulina, 2003).

A presente tarefa, base para introdução das próximas tabuadas, é organizada em três partes $(\mathrm{a}, \mathrm{b}$ e c) e será desenvolvida em equipes. Cada equipe receberá duas malhas quadriculadas com as seguintes medidas:

Equipe a: 6 × 15 e $6 \times 12$

Equipe b: $5 \times 14$ e $5 \times 11$

Equipe c: 7 x 17 e 7 x 12

Equipe d: $8 \times 18$ e $8 \times 13$

Vale esclarecer que as crianças não terão acesso aos registros anteriormente apresentados, pois serão construídos durante a resolução da tarefa. A título de exemplificação, apresentaremos o material que receberá a primeira equipe (Figura 14).

$\mathrm{O}$ enunciado da primeira parte da tarefa consiste no seguinte:

Tarefa 4: a) Registre, no esquema, o valor da unidade de medida intermediária e a quantidade de vezes que esta se repete em cada superfície quadriculada. Na sequência, componha a expressão que representa o total de medidas básicas das duas superfícies (Davýdov et al., 2009).

As duas malhas quadriculadas, que cada equipe recebe, possuem o mesmo comprimento da altura e se diferem no comprimento da largura. Porém, vale ressaltar que o comprimento da altura das malhas de cada equipe varia. Nas malhas da 


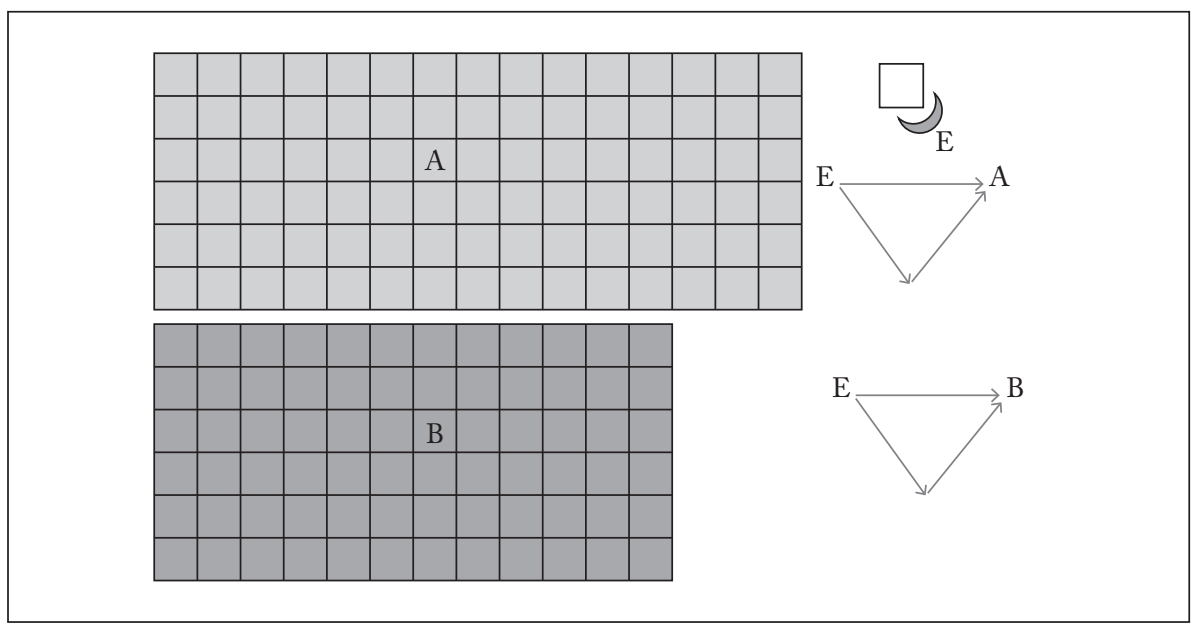

Figura 14 - Tarefa 4: superfícies A e B da equipe a

Fonte: Elaboração nossa com base na proposição davydoviana (Davýdov et al., 2009, p. 51-52).

equipe a, por exemplo, o comprimento da altura mede seis (6) unidades. Nos demais pares de malhas, as medidas dos comprimentos são, respectivamente: cinco (5), sete (7) e oito (8) (Gorbov e Mikulina, 2003).

A tarefa consiste na composição de uma expressão para o cálculo das áreas das duas superfícies que cada equipe recebeu. $\mathrm{O}$ professor questiona: Por onde vamos começar? $\mathrm{O}$ professor sugere analisar primeiro os esquemas. De acordo com estes, a unidade de medida básica $E$ é constituída por um quadrado da malha. Então, como proceder para calcular a área da superfície de cada figura? Contar cada quadradinho, de um em um, como fazem as crianças do primeiro ano? Já aprendemos a construir a medida intermediária; logo, vamos construí-la para as duas superfícies (Gorbov e Mikulina, 2003).

Cada equipe realiza a medição das superfícies que receberam e registram o resultado nos respectivos esquemas. Como a medida do comprimento da altura é a mesma, em cada par de malhas, essa medida é considerada, por todas as equipes, unidade intermediária. A título de ilustração, continuaremos com o exemplo da primeira equipe. Por meio de contagem, as crianças constatam, na primeira malha (Figura 14), que a coluna é composta de seis (6) unidades básicas e que são quinze (15) colunas no total. Esses valores são registrados no esquema, seguidos da expressão 6 × 15 (Gorbov e Mikulina, 2003). O mesmo procedimento ocorre na segunda malha. Novamente, a coluna é considerada como unidade de medida intermediária. Assim, são seis (6) unidades básicas que se repetem por doze (12) vezes (Figura 15).

$\mathrm{O}$ professor esclarece que a medida do comprimento da altura do par de malhas varia de uma equipe para outra e sugere que compartilhem os diferentes resultados obtidos, que são registrados no quadro (Figura 16).

As crianças constatam que, em cada par de esquemas (Figura 16), os valores das unidades de medidas intermediárias são iguais (6 e 6; 5 e 5; 7 e 7; 8 e 8). Então o professor questiona: Podemos elaborar um par de esquemas que seja válido para 


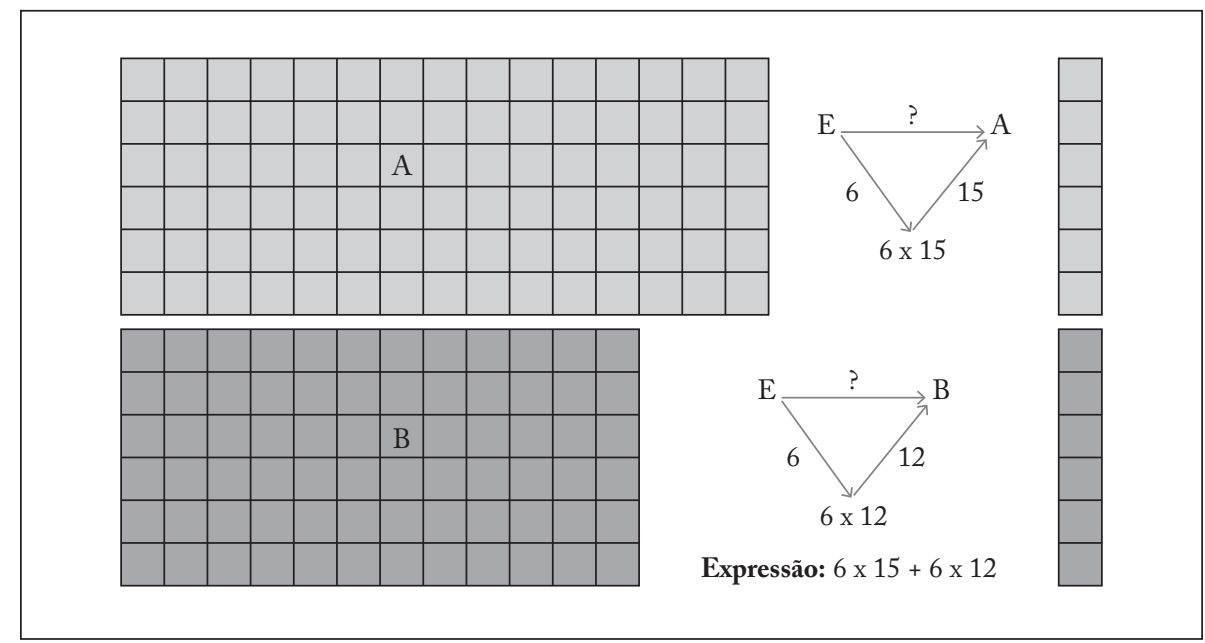

Figura 15 - Tarefa 4: a) registro do processo de medição das superfícies A e B

Fonte: Elaboração nossa com base na proposição davydoviana (Davýdov et al., 2009).

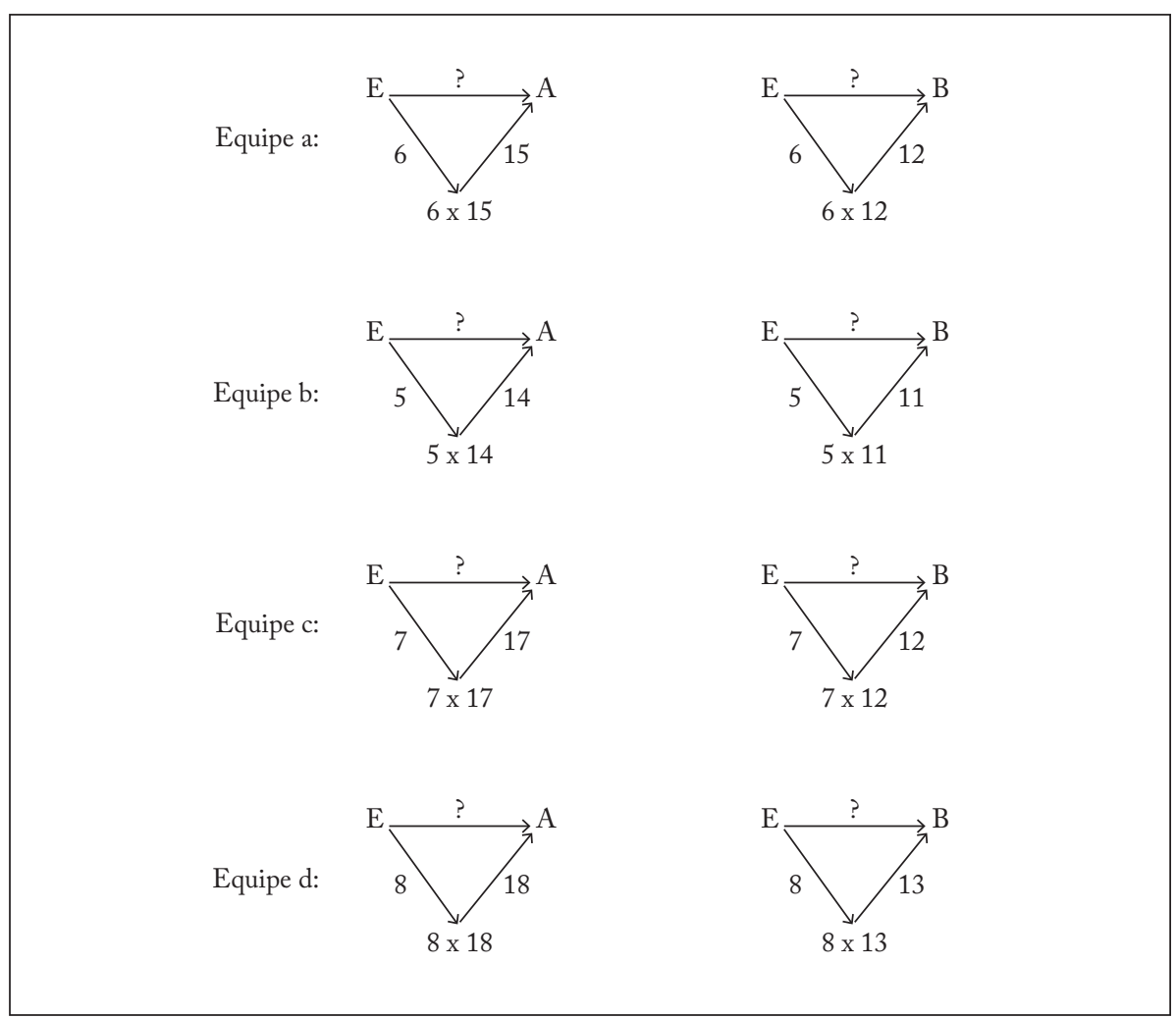

Figura 16 - Tarefa 4: registro dos esquemas no quadro

Fonte: Elaboração nossa com base na proposição davydoviana (Davýdov et al., 2009). 
todos os quatro (4) distribuídos na classe? É possível substituir os números por letras? (Gorbov e Mikulina, 2003).

Como as unidades de medidas intermediárias em cada par de esquemas é a mesma, serão representadas pela letra $a$ (Figura 17). A diferença entre os valores correspondentes ao número de vezes que a unidade de medida intermediária foi tomada, em cada esquema, impede a adoção da mesma letra. De outro modo, em cada superfície, a unidade de medida intermediária repetiu-se uma quantidade de vezes diferente. Para tanto, como ilustração, adotaremos as letras $b$ e $c$. Logo abaixo do esquema são registradas as respectivas expressões literais (Gorbov e Mikulina, 2003).
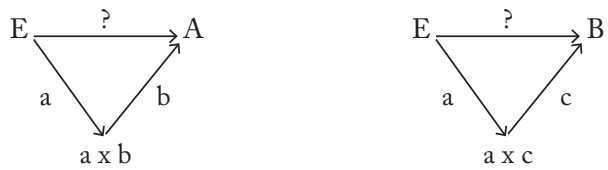

Expressão literal: $a \times b+a \times c$

Figura 17 - Tarefa 4: a) esquema genérico e expressão literal

Fonte: Elaboração nossa com base na proposição davydoviana (Davýdov et al., 2009).

A continuidade da tarefa consiste na determinação da diferença entre as medidas.

Tarefa 4: b) Determine a diferença entre as medidas A e B, conforme a Figura 18 (Davýdov et al., 2009).

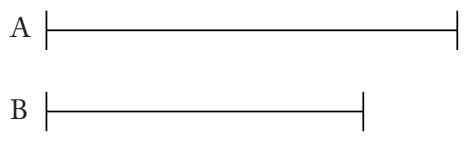

Figura 18 - Tarefa 4: b) representação gráfica da relação entre as grandezas

Fonte: Elaboração nossa com base na proposição davydoviana (Davýdov et al., 2009, p. 51-52).

A partir da análise dos segmentos (Figura 18), as crianças concluirão que $\mathrm{A}$ é maior que $\mathrm{B}(\mathrm{A}>\mathrm{B})$. O professor questiona: Como proceder para determinar a diferença entre as medidas? (Gorbov e Mikulina, 2003).

A diferença corresponde a uma parte desconhecida que, adicionada à outra parte (B), resulta na parte maior (A) (Figura 19). Nesse caso, a operação indicada para determinar o valor desconhecido é a subtração: $(a \times b)-(a \times c)$ (Gorbov e Mikulina, 2003).

A expressão genérica, anteriormente apresentada, possibilita a resolução do problema por todas as equipes. Na especificidade da primeira equipe, temos (Figura 20). 


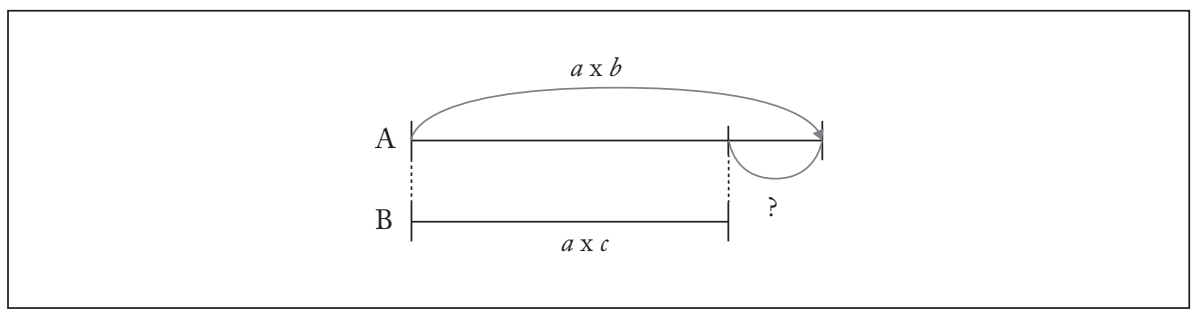

Figura 19-Tarefa 4: b) comparação entre as medidas A e B

Fonte: Elaboração nossa com base na proposição davydoviana (Davýdov et al., 2009).

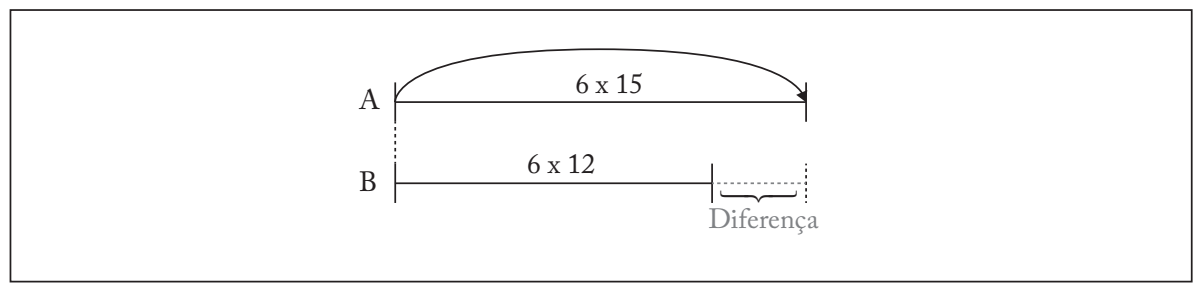

Figura 20 - Tarefa 4: b) comparação das medidas A e B da primeira equipe

Fonte: Elaboração nossa com base na proposição davydoviana (Davýdov et al., 2009).

O processo de resolução consiste no seguinte: $(6 \times 15)-(6 \times 12)=$ $90-72=18$, mas a resolução da tarefa continua.

Tarefa 4: c) Represente, no esquema de setas, outro modo de determinar a diferença entre as medidas A e B (Gorbov, Mikulina e Savieliev, 2003).

A diferença entre as medidas pode ser determinada a partir da sobreposição das superfícies, conforme Figura 21 (Gorbov e Mikulina, 2003).

Ao sobrepor as superfícies, verifica-se que a unidade de medida intermediária seis (6) coube poucas vezes na diferença: apenas três (3) vezes. Essa conclusão pode ser representada no esquema com setas, conforme Figura 22 (Gorbov e Mikulina, 2003).

$\mathrm{O}$ professor questiona: Para determinar a diferença entre as medidas A e B, é necessário calcular cada uma delas separadamente, conforme procedemos anteriormente? A partir da análise do procedimento realizado na Figura 20, as crianças

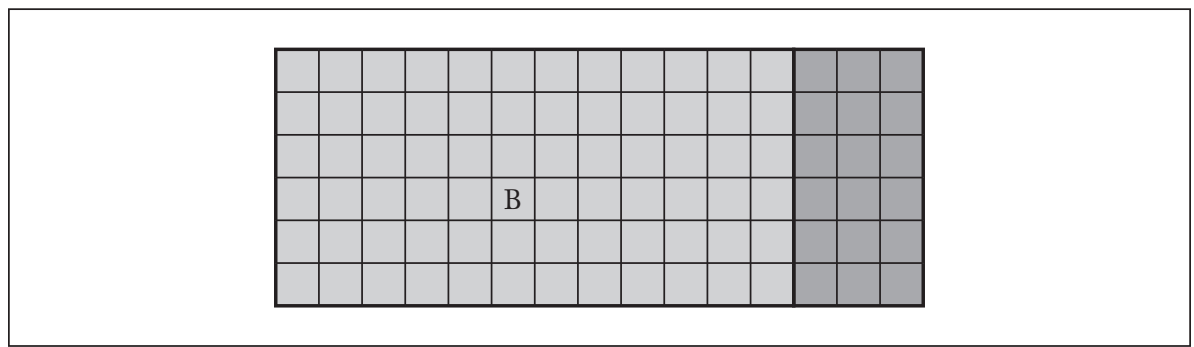

Figura 21 - Tarefa 4: c) sobreposição das superfícies A e B

Fonte: Elaboração nossa com base na proposição davydoviana (Davýdov et al., 2009). 

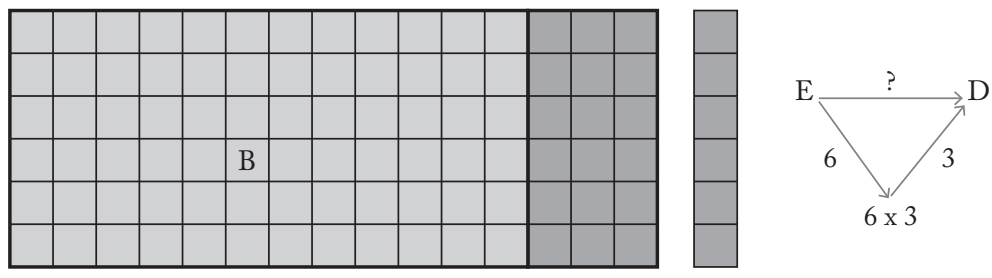

Figura 22 - Tarefa 4: c) outro modo de determinar a diferença

Fonte: Elaboração nossa com base na proposição davydoviana (Davýdov et al., 2009).

concluirão, com orientação do professor, que a diferença poderia ser identificada a partir da sobreposição das superfícies (Figura 22) e, posteriormente, calculada (Gorbov e Mikulina, 2003).

O professor propõe a seguinte reflexão: Por meio do trabalho realizado, determinamos dois modos distintos de calcular a diferença entre as medidas A e B: primeiro, compomos expressões para calcular, separadamente, a área de cada superfície (Figura 17). Em seguida, sobrepomos as superfícies e compomos uma única expressão para determinar a diferença (Figura 22). Esse movimento pode ser representado também por meio dos esquemas, conforme Figura 23 (Gorbov e Mikulina, 2003).
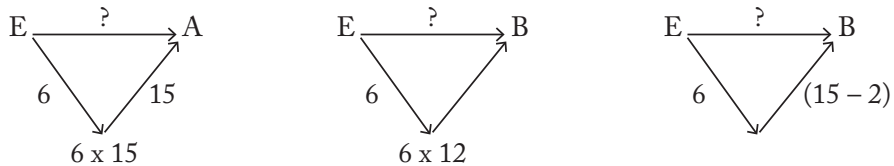

Figura 23 - Tarefa 4: c) outro modo de determinar a diferença

Fonte: Elaboração nossa com base na proposição davydoviana (Davýdov et al., 2009).

Para calcular a diferença a partir do primeiro método, $(6 \times 15)-(6 \times 12)$, multiplicam-se os números apresentados entre parênteses e, em seguida, subtraem-se os resultados $(90-72=18)$. No segundo método, $6 \times(15-12)$, subtraem-se os números que estão entre parênteses $(15-12=3)$ e multiplica-se o resultado (3) por $6: 6 \times 3=18$. Genericamente, o segundo método consiste no seguinte (Figura 24).

Esse duplo procedimento expressa uma propriedade matemática, a multiplicação de um número pela diferença: $a \times(b-c)=(a \times b)-(a \times c)$.

Para multiplicar um número pela diferença entre dois números, pode-se multiplicar esse número, separadamente, pelo minuendo e pelo subtraendo e, depois, determinar a diferença entre os resultados (Gorbov e Mikulina, 2003). Trata-se da propriedade distributiva da multiplicação em relação à subtração. 

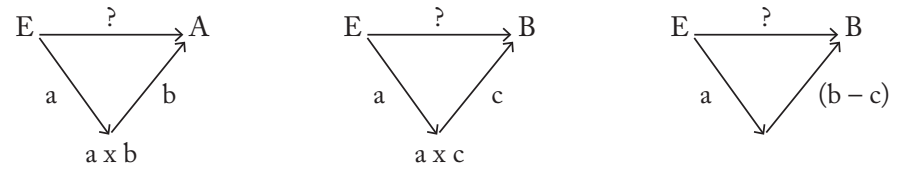

Figura 24-Tarefa 4: c) genericamente

Fonte: Elaboração nossa com base na proposição davydoviana (Davýdov et al., 2009).

$\mathrm{Na}$ tarefa em análise, Davýdov e colaboradores envolveram vários elementos que subsidiam a resolução, tais como malhas quadriculadas, composição de esquemas, cálculo da diferença das medidas A e B (Figuras 14, 18 e 21), entre outras. Nesse processo, o modelo da tabuada sofreu várias transformações. No contexto da tarefa de estudo, essas variações referem-se à terceira ação: transformação do modelo da relação universal para o estudo de suas propriedades em forma pura (Davídov, 1988). A transformação dos dados da tarefa ocorre de diversos modos: na forma objetal, gráfica, literal e construção e reconstrução do próprio modelo.

A transformação do modelo é realizada pela criança em duas direções. No começo, os alunos constroem o modelo durante ou depois da manipulação do material objetal. Em seguida, de modo inverso, segundo o modelo dado, a criança deve realizar as correspondentes manipulações. (Davídov, 1988, p. 213)

Como Davýdov (1982) afirma, a transformação do modelo ocorre em duas direções: do objeto (relação entre grandezas) para o modelo (gráfico, literal), e do modelo para as diferentes manifestações. Inicialmente (Figura 15), os dados da tarefa em análise, apresentados na forma objetal (área das malhas quadriculadas, unidades de medida intermediária e quantidade de vezes que ela se repete) são modelados na forma aritmética e gráfica (Figura 16) e, posteriormente, na forma literal (Figura 17).

Nesse processo, a transformação também ocorre em direção inversa, do próprio modelo, com suas propriedades na forma pura para a objetal. Isto é, a partir do modelo gráfico são realizadas variações na relação essencial. Para tanto, os valores correspondentes às unidades de medida intermediária e o total de vezes que elas se repetem são alterados (Figura 16). Por meio da análise da relação essencial obtêm-se diferentes tabuadas (de cinco, seis, sete e oito) e seus respectivos resultados singulares (representados pelo ponto de interrogação).

A transformação do modelo também ocorre quando são dadas novas condições de medição, como para determinar a diferença entre as medidas A e B representadas no esquema de segmentos (Figura 18). Esse esquema possibilita a análise da relação inversa entre as operações de adição e subtração e suas relações com a tabuada. É peculiar da operação de subtração a propriedade fundamental: para determinar a diferença entre dois segmentos, subtrai-se, do comprimento do segmento maior $(a \times b)$, o comprimento do segmento menor $(a \times c)$. O terceiro segmento corresponde à parte desconhecida (diferença). Logo, é possível compor uma expressão genérica, que representa a diferença entre as medidas dos segmentos: $a \times b-a \times c=d$ (Figura 19). 
Os modelos expressos com letras, os modelos gráfico-espaciais cumprem um importante papel na formação dos conceitos matemáticos. Sua particularidade essencial é que reúnem o sentido abstrato com o concreto objetal. Falando estritamente, a abstração da relação matemática pode ser produzida somente com a ajuda das fórmulas expressadas por meio de letras. Porém, nelas se fixam apenas os resultados das ações realizadas real ou mentalmente com os objetos, enquanto as representações espaciais (por exemplo, segmentos ou retângulos) têm uma grandeza visível [extensão], permitindo às crianças realizar transformações reais cujos resultados não só se podem supor, mas também observar. (Davídov, 1988, p. 213-214).

Os modelos expressos por meio de segmentos e letras (Figuras 18,19 e 20) refletem o cálculo da diferença entre as áreas com medida $\mathrm{A}$ e $\mathrm{B}$, no plano objetal (Figuras 21 e 22). As grandezas consideradas são as mesmas; porém, em condições diferentes. Portanto, a sobreposição das superfícies com medida A e B foi fundamentada na propriedade matemática da subtração, mencionada anteriormente. Assim, ocorre uma nova generalização e abstração (Figura 25). Esta é expressa pela propriedade distributiva da multiplicação em relação à subtração $a \times b-a \times c=$ $a \times(b-c)$. Nesse sentido,

[...] a modelação está ligada ao caráter visual amplamente utilizado pela didática tradicional. Contudo, no marco do ensino experimental [proposição davydoviana], o caráter visual tem um conteúdo específico. Nos modelos visuais se refletem as relações e as vinculações essenciais ou internas do objeto, separadas (abstraídas) por meio das correspondentes transformações (o visual concreto habitualmente somente fixa as propriedades externamente observáveis das coisas [lógica formal]). (Davídov, 1988, p. 214, grifos do original)

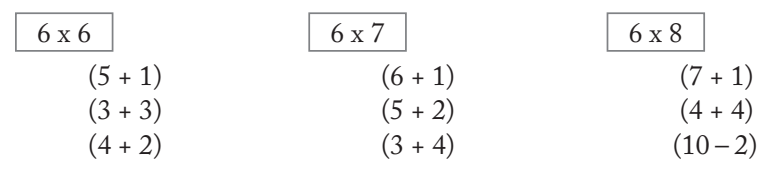

Figura 25 - Tarefa 5: produto do número seis (6) pelas regras da soma e diferença

Fonte: Elaboração nossa com base na proposição davydoviana (Davýdov et al., 2009, p. 64).

O caráter visual contemplado, na tarefa em análise, por meio das áreas e dos esquemas com setas e segmentos reflete as relações entre as unidades de medidas básica e intermediária e a quantidade de vezes que se repetem. Trata-se das vinculações das características internas da tabuada. Assim, o trabalho com o "modelo aparece como o processo pelo qual se estudam as propriedades da abstração substancial da relação universal” (Davídov, 1988, p. 183). As propriedades da abstração substancial formam o conteúdo do modelo. Este "fixa as características internas do objeto, não observáveis de maneira direta” (Davídov, 1988, p. 183). 
O estudo da relação essencial da tabuada é imprescindível para a formação do procedimento geral, cujo objetivo é solucionar a tarefa de estudo e "assim formar o conceito do 'núcleo' do objeto. Entretanto, a adequação do 'núcleo' a seu objeto é revelada quando dele se extraem as múltiplas manifestações particulares”(Davídov, 1988, p. 183, grifos do original). Esta constitui a quarta ação de estudo, que será abordada na Tarefa 5.

Tarefa 5: Determine os produtos de 6 6 6, 6 × 7 e 6 × 8 (Figura 25) (Davýdov et al., 2009).

A tarefa consiste em determinar os produtos $(6 \times 6 ; 6 \times 7$ e $6 \times 8)$ a partir das propriedades estudadas nas tarefas anteriores. O segundo fator é considerado soma ou diferença entre dois números. A resolução da tarefa é concretizada na Figura 26, do seguinte modo (Gorbov e Mikulina, 2003).

A partir da análise do processo de desenvolvimento da tarefa (Figura 26), as crianças concluem, com o auxílio do professor, que se trata da tabuada do número seis (6) em sua totalidade (Gorbov e Mikulina, 2003). Analisemos, por exemplo, o produto de $6 \times 6$, considerando o segundo fator (6) como soma $(4+2)$. A partir da regra do produto de um número pela soma $6 \times(4+2)$, temos $(6 \times 4)+(6 \times 2)$. $\mathrm{Na}$ linha seguinte são apresentados os respectivos resultados (24 e 12). Esse movimento permite inferir que $6 \times 4=24$ e 6 × $2=12$.

Os valores desconhecidos referem-se apenas aos produtos concernentes a $6 \times 6,6 \times 7$ e $6 \times 8$. Esses foram determinados a partir dos resultados conhecidos, decorrentes da própria tabuada do número seis (6). Didaticamente, esse é um dos modos adotados por Davýdov e colaboradores para as crianças memorizarem as tabuadas estudadas.

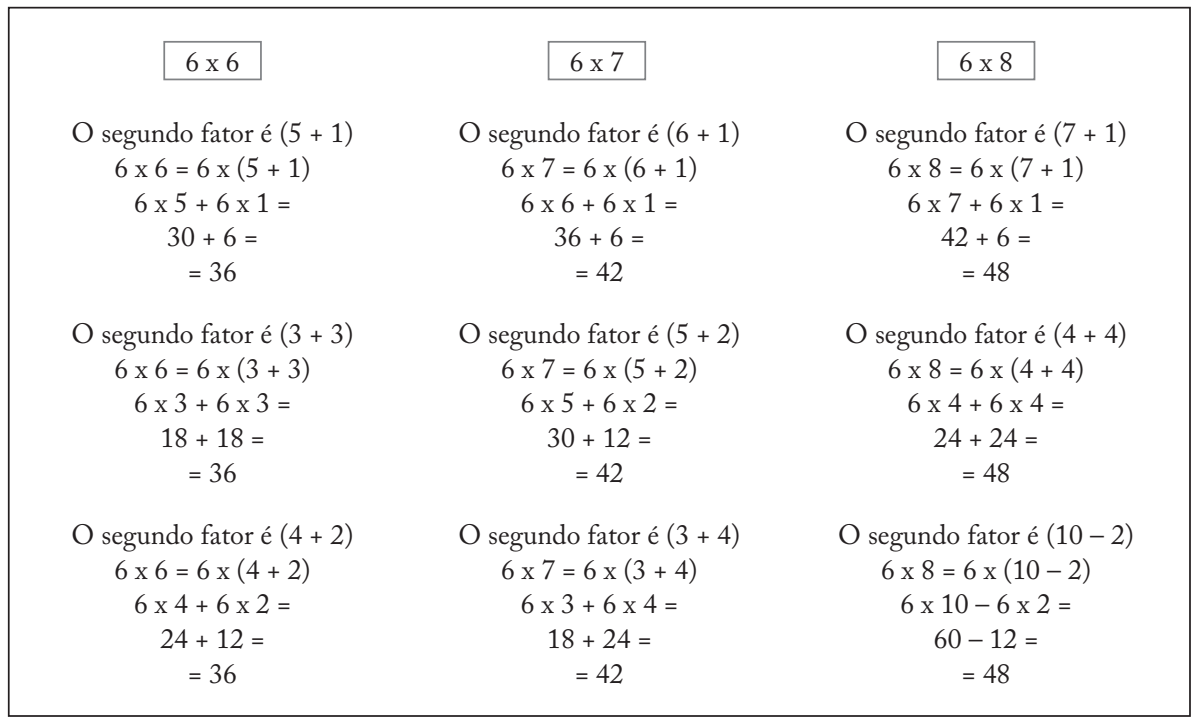

Figura 26 - Tarefa 5: aplicação da propriedade distributiva na tabuada de seis (6)

Fonte: Elaboração nossa com base na proposição davydoviana (Davýdov et al., 2009). 
No contexto da tarefa de estudo, esse procedimento (Figura 26) está relacionado à quarta ação: construção de um sistema de tarefas particulares que podem ser resolvidas por um procedimento geral (Davídov, 1988).

Após a determinação do modelo da tabuada na forma literal, a tarefa de estudo é concretizada por meio de diversas tarefas particulares. Para Davídov (1988), as tarefas particulares podem ser resolvidas por um processo único, geral, desenvolvido durante as ações de estudo anteriores.

Mas qual é o procedimento geral que foi apresentado anteriormente para o conceito de tabuada? Vale relembrar que a tabuada apresenta uma sequência de sentenças (fatores), cujos resultados (produtos) conformam uma sequência numérica, na qual cada termo posterior é a soma do anterior, mais uma unidade de medida intermediária. $\mathrm{Ou}$, ainda, cada produto da tabuada é resultado da soma ou da subtração de $n$ vezes a unidade de medida intermediária.

O caráter eficaz desse procedimento se verifica, justamente, na solução de tarefas particulares; os estudantes as enfocam como variantes da tarefa de estudo inicial e imediatamente [...] separam em cada uma a relação geral, orientando-se pela qual podem aplicar o procedimento geral de solução assimilado. (Davídov, 1988, p. 183)

Após a dedução do procedimento geral de solução desenvolvido nas tarefas precedentes, o passo seguinte consistiu em aplicá-lo nas sentenças correspondentes (Figura 26). Assim, nas sentenças $6 \times 6=6 \times(5+1), 6 \times 7=6 \times(6+1)$ e $6 \times 8=$ $6 \times(7+1)$, o procedimento geral aplicado foi: cada termo posterior é a soma do anterior mais uma unidade de medida intermediária. E, nas demais sentenças, cada produto da tabuada é resultado da soma ou da subtração de $\mathrm{n}$ vezes a unidade de medida intermediária (Figura 26).

As quatro ações de estudo analisadas estão dirigidas para que

os estudantes revelem as condições do surgimento do conceito do qual estão em processo de apropriação (para que e como se separa seu conteúdo, por que e em que este se fixa, em que casos particulares se manifesta depois). É como se os próprios estudantes construíssem o conceito, embora com a direção sistemática do professor (ao mesmo tempo o caráter dessa direção muda gradativamente e cresce, também gradativamente, o grau de autonomia do estudante). (Davídov, 1988, p. 183-184)

O desenvolvimento das ações de estudo, promovido durante a realização das tarefas particulares, tem como função primordial conduzir as ações dos estudantes para a apropriação do conceito. No movimento do conhecimento, a tarefa em análise refere-se ao concreto ponto de chegada. Como mencionamos na introdução do presente texto, o concreto e o abstrato são momentos do movimento do processo de conhecimento: concreto ponto de partida (abstrato) e concreto ponto de chegada. 
O concreto ponto de chegada "não se trata de algo sensorial, mas mental, fecundado pelo conhecimento graças às abstrações da essência, reduzidas a uma mesma base" (Ilienkov, 2006, p. 160). No início do processo do conhecimento da tabuada, tínhamos o concreto sensorialmente perceptível por meio das relações entre grandezas. Por meio da análise dessas relações, foi possível reduzi-las à seguinte abstração: $a \times(n-1)+a=c$. A partir desse núcleo, Davýdov e colaboradores apresentam diversas tabuadas particulares, cada qual com suas singularidades, agora em nível de concreto pensado.

Na proposição davydoviana, "quando os estudantes formam o procedimento geral de solução da tarefa de estudo lhes propõe o emprego [desse procedimento] para solucionar tarefas práticas" (Davídov, 1988, p. 216). O autor em referência relata que os estudantes resolviam esse tipo de tarefa "rapidamente, sem manifestar externamente o processo de análise dos dados" (Davídov, 1988, p. 216-217). Portanto, ao pensarmos a proposição davydoviana em nosso contexto educacional, após o estudo da relação essencial, universal, da tabuada, seria possível proceder a resolução dos problemas propostos nos livros didáticos brasileiros.

\section{CONSIDERAÇÕES FINAIS}

A tabuada, em Davýdov, surge como resultado de um movimento conceitual que envolve o geral, universal, particular e singular. O geral, para todos os conceitos matemáticos, são as grandezas. Para cada conceito há uma relação essencial que, na especificidade da tabuada, é constituída pelas unidades de medidas básicas e intermediárias e o seu total. O estudo dessa conexão interna implica a análise da relação entre o universal, o singular e o particular. É por meio dessa relação que o universal se manifesta em forma de lei, conforme o esquema na Figura 27.

Esse esquema (Figura 27) representa a essência, a relação inicial que dá origem a todas as tabuadas. No modelo universal da tabuada, $a \times(n-1)+a=c$, o elo que une o universal e o singular é o particular. Este consiste no número $a$, na unidade de medida intermediária. Com a variação de $a$, obtemos as diferentes tabuadas particulares $(a=4, a=5, a=6, \ldots)$. Mantendo o número $a$ fixo e variando o valor de $n$, obtemos as diferentes singularidades para cada tabuada particular. Por exemplo, tomemos uma particularidade, a tabuada do número seis (6); ao variarmos $n$, temos as seguintes singularidades: $6 \times 1=6 ; 6 \times 2=12 ; 6 \times 3=18, \ldots$ Assim, a tabuada

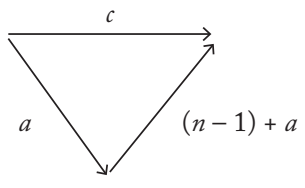

Figura 27 - Esquema da relação essencial da tabuada

Fonte: Elaboração nossa, 2014. 
particular do número seis (6) surge como resultado da relação entre o universal, o particular e o singular.

É esse movimento conceitual, fundamentado nos princípios da lógica dialética, que sustenta a proposição davydoviana para o ensino da tabuada, com vistas ao desenvolvimento do pensamento teórico. Tal pensamento, de acordo com Davýdov (1982), não surge e nem se desenvolve na vida cotidiana, mas somente em tal ensino, cujos programas se baseiam na compreensão dialética do pensamento.

De acordo com Rosa (2012), são poucas as proposições brasileiras que promovem o desenvolvimento do pensamento teórico. Portanto, vislumbramos, na proposição davydoviana, uma das possibilidades para repensarmos o processo de ensino e aprendizagem de matemática em nosso país.

\section{REFERÊNCIAS}

Bernshléin, N. Chébishev y su influencia en el desarrollo de las matemáticas. Memorias científicas de la Universidad Estatal de Moscú, fasc. 9 I, I 947.

DavÝDov, V. V. Tipos de generalización en la enseñanza. 3. ed. Habana: Pueblo y Educación, 1982.

Davídov, V. V. La enseñanza escolar y el desarrollo psíquico: investigación teórica y experimental. Tradução de Marta Shuare. Moscú: Progreso, 1988.

DavÝdov, V. V. et al. Matemática. $3^{\circ}$ ano: livro didático e de exercícios do ensino fundamental. 7. ed. Tradução de Ediséia Suethe Faust Hobold e Josélia Euzébio da Rosa. Moscú: Vita- Press, 2009. [Tradução realizada a título de pesquisa].

Davýdov, V. V. et al. Matemática. $2^{\circ}$ ano: livro didático e de exercícios do ensino fundamental. 3. ed. Tradução de Ediséia Suethe Faust Hobold e Josélia Euzébio da Rosa. Moscú: Vita- Press, 2012. [Tradução realizada a título de pesquisa].

Gorbov, S. F.; Mikulina, G. G. Ensino de matemática. $3^{\circ}$ ano: livro do professor do ensino fundamental. 3. ed. Tradução de Elvira Kim. Moscú: Vita- Press, 2003. [Tradução realizada a título de pesquisa].

Gorbov, S. F.; Mikulina, G. G.; Savieliev, O. V. Ensino de matemática. $3^{\circ}$ ano: livro do professor do ensino fundamental. (sistema do D. B. Elkonin - V.V. Davidov). Tradução de Ediséia Suethe Faust Hobold e Josélia Euzébio da Rosa. Moscú: Vita-Press, 2003. [Tradução realizada a título de pesquisa].

. Ensino de matemática. $2^{\circ}$ ano: livro do professor do ensino fundamental. 3. ed. Tradução de Elvira Kim. Moscú: Vita- Press, 2009. [Tradução realizada a título de pesquisa].

Новоцd, E. S. F. Proposições para o ensino da tabuada com base nas lógicas formal e dialética. 2014. 199f. Dissertação (Mestrado em Educação) - Universidade do Sul de Santa Catarina, Tubarão, 2014.

Ilienkov, E. V. La ascensión de lo abstracto a lo concreto en principios de la lógica dialéctica. In: Jiménez, A. T. Teoría de la construcción del objeto de estudio. México: Instituto Politécnico Nacional, 2006. p. 151-200. 
LibÂNeo,J. C.; Freitas, R. A.M. M. Vasily Vasilyevich Davydov: a escola e a formação do pensamento teórico-científico. In: Longarezi, A. M.; Puentes, R. V. (Orgs.). O ensino desenvolvimental: vida, pensamento e obra dos principais representantes russos. Uberlândia: EDUFU, 2013. p. 315-350.

Panossian, M. L. O movimento histórico e lógico dos conceitos algébricos como princípio para constituição do objeto de ensino da álgebra. 2014. 317f. Tese (Doutorado em Educação) Faculdade de Educação da Universidade de São Paulo, São Paulo, 2014.

Rosa, J. E. Proposições de Davydov para o ensino de matemática no primeiro ano escolar: inter-relações dos sistemas de significações numéricas. 2012. 244f. Tese (Doutorado em Educação) - Universidade Federal do Paraná, Curitiba, 2012.

Rosental, M. M. Princípios de logica dialectica. Tradução de Augusto Vidal Boget. Montevidéu: Pueblos Unidos, 1962.

Rosental, M. M.; Straks, G. M. Categorías del materialismo dialectico. Tradução de Adolfo Sanchez Vazquez e Wenceslao Roces. México: Grijalbo, 1965.

Shuare, M. La psicología soviética tal como yo la veo. Moscú: Progresso, 1990.

Shtoff, V.A. Modelírovanie ifilosofía. El modelado y la filosofía. Moscú: "Naúka”, 1966. Sternin, A. O. O singular, o particular e o universal. In: Rosental, M. M.; Straks, G. M. (Orgs.). Categorias del materialismo dialectico. Tradução de Adolfo Sanchez Vazquez e Wenceslao Roces. México: Grijalbo, 1965. p. 257-297.

Vigotski, L. S. A construção do pensamento e da linguagem. Tradução de Paulo Bezerra. São Paulo: Martins Fontes, 2000.

\section{SOBRE AS AUTORAS}

Ediséia Suethe Faust Hobold é mestre em educação pela Universidade do Sul de Santa Catarina (UNISUL). Professora da Escola de Educação Básica São Ludgero.

E-mail: ediseiafhobold@yahoo.com.br

Josélia EuzÉbio da Rosa é doutora em educação pela Universidade Federal do Paraná(UFPR). Professora da Universidade do Sul de Santa Catarina (UNISUL). E-mail: joselia.rosa@unisul.br

Recebido em 6 de maio de 2015 Aprovado em 28 de setembro de 2015 